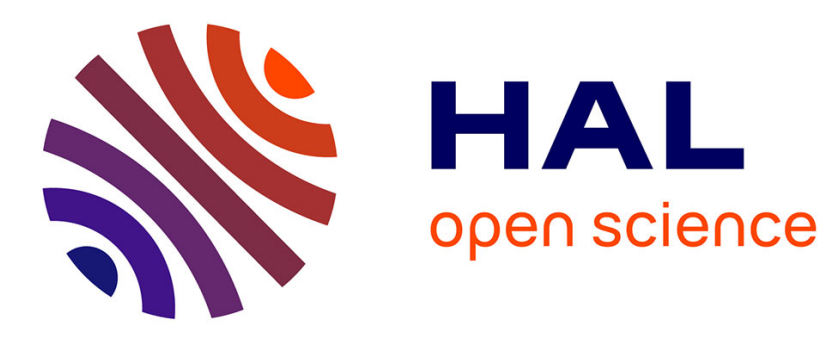

\title{
Wireless passive high-doses radiation sensor
}

Émilie Debourg, Ayoub Rifai, Hervé Aubert, Patrick Pons, Isabella

Augustyniak, Pawel Knapkiewicz, Jan Dziuban, Michal Matusiak, Michal

Olszacki

\section{- To cite this version:}

Émilie Debourg, Ayoub Rifai, Hervé Aubert, Patrick Pons, Isabella Augustyniak, et al.. Wireless passive high-doses radiation sensor. IEEE sensors 2014, Nov 2014, Valencia, Spain. 4p. hal-01053068

\section{HAL Id: hal-01053068 \\ https://hal.science/hal-01053068}

Submitted on 29 Jul 2014

HAL is a multi-disciplinary open access archive for the deposit and dissemination of scientific research documents, whether they are published or not. The documents may come from teaching and research institutions in France or abroad, or from public or private research centers.
L'archive ouverte pluridisciplinaire HAL, est destinée au dépôt et à la diffusion de documents scientifiques de niveau recherche, publiés ou non, émanant des établissements d'enseignement et de recherche français ou étrangers, des laboratoires publics ou privés. 


\section{Wireless passive high-doses radiation sensor}

\author{
E Debourg, A Rifai, H. Aubert, P. Pons \\ CNRS, LAAS, 7 Av. Roche, F-31400 Toulouse, France \\ Univ de Toulouse, LAAS, F-31400 Toulouse, France \\ I. Augustyniak, P. Knapkiewicz, J. Dziuban \\ Wrocław University of Technology, Wrocław, Poland
}

\author{
M. Matusiak, M.Olszacki \\ National Centre for Nuclear Research, Otwock, Poland
}

\begin{abstract}
The high dose measurement techniques are of the great interest in nuclear engineering for both, industrial and academic community. Related to these very harsh environment, today sensors solutions are based on external post analysis that not allow real time monitoring. Wireless monitoring of fully chipless passive sensors has been demonstrated for the first time using miniaturized HPD (Hydrogen Pressure Dosimitry) solution. We obtained micrometric silicon membrane deflection for several ten of $\mathrm{kGy}$ using $6 \mathrm{MeV}$ electron beam.)
\end{abstract}

Keywords - Radiation dosimeter, polymer radiolysis, MEMS

\section{INTRODUCTION}

The dosimetry is one of the crucial techniques that are needed to assure personal safety and facilities security in the areas of high radioactivity as nuclear power plants or powerful experimental research infrastructure (LHC, XFEL, ITER). Until now, the common electronic dosimeters are based on the silicon diodes or field effect transistors what limits the measured dose value up to $10 \mathrm{kGy}$, as the higher levels lead to the device saturation. The other techniques that allows for higher dose measurement (up to $1 \mathrm{MGy}$ and more) are based mostly on the variation of physic-chemical parameters of different materials but need the post measurement treatment of the sensor that has to be taken out of the monitored zone and use of the special equipment what makes the continuous measurement impossible.

The solution that may overcome that problem, and that was already proposed by the authors, is the use of passive pressure sensors that are interrogated by radar technique [1] and coupled with a micro-cavity filled with polymer that outgases under irradiation [2] (Fig.1 and Fig.2). In this paper, we report on the last progresses done on this project.

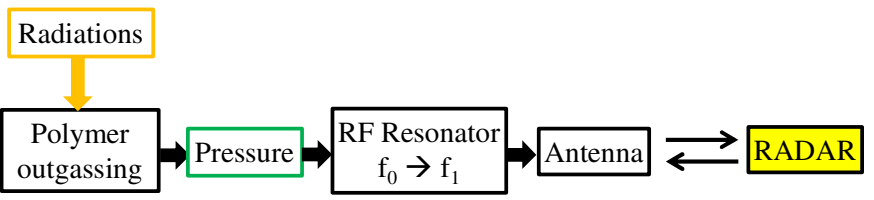

Fig. 1. Sensor principle

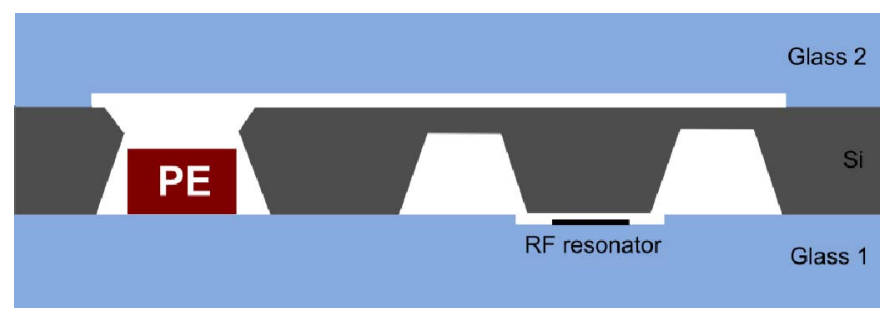

Fig. 2. Transducer principle

II. MATERIAL STUDY

\section{A. Glass}

A direct RF analysis has been done in order to verify that the RF glass properties are stable under irradiation. We analyzed the shift of resonant frequency (around $34 \mathrm{GHz}$ ) of a planar RF resonator (Fig.3). The resonator is obtained through $1 \mu \mathrm{m}$ thick aluminum layer deposited by PVD (Physical Vapor Deposition) on a $500 \mu \mathrm{m}$ thick Borofloat 33 glass substrate.

Resonators have been irradiated by high energy $(6 \mathrm{MeV})$ electron with two sets of doses ( $\cong 160 \mathrm{kGy}$ and $\cong 190 \mathrm{kGy})$. The resonant frequency shift after irradiation is lower than $\pm 0.6 \%$ (measurement reproducibility) (Fig.4).

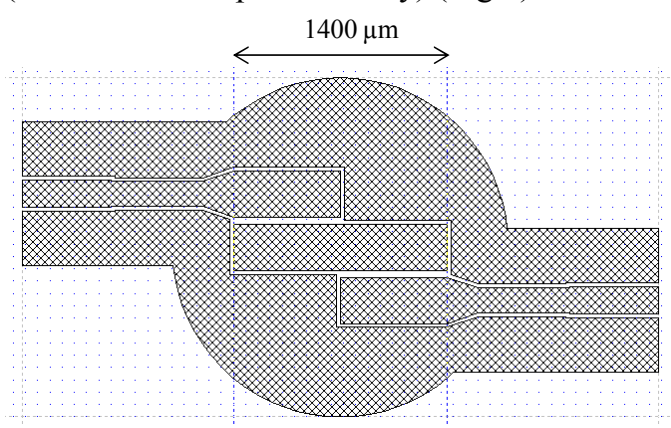

Fig. 3. Design of planar RF resonator 


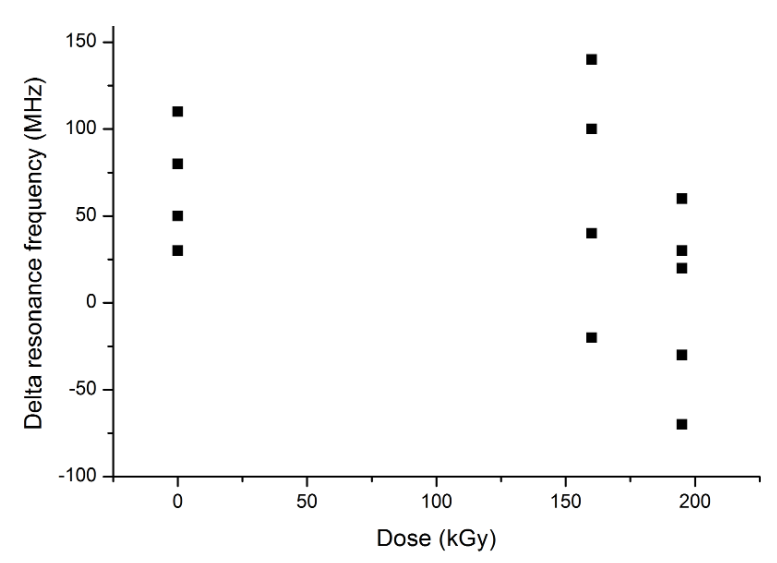

Fig. 4. Resonant frequency shift versus irradiation dose (4 samples)

\section{B. Silicon}

Silicon, from the mechanical point of view, is highly resistant to gamma and neutron irradiation. The only effects of neutron irradiation is a transmutation to phosphorus (slight variation of Young modulus ) and the evolution of helium nuclei (alpha particles) in case of Boron doped Silicon (outgassing). But in our case, high resistivity silicon (without boron doping) will be used to reduce the RF losses.

To verify the small variation of Young modulus under neutron, we performed a set of nano-indentations tests before and after neutron irradiation in external channel (Fluence equal to $10^{12} \mathrm{~N} / \mathrm{cm} 2$ ). The nano-indentations have been done using the state of the art Nanotest system from Micromaterials Company using Berkovich type indent head. For each silicon sample, 5 indentation points have been performed and mean value is extracted. Tests have been performed on low resistivity and high resistivity silicon (both $\mathrm{n}$ and $\mathrm{p}$ type) and on 4 different samples from each type. We can conclude than the Young modulus shift after neutron irradiation is lower than $0.6 \%$ (that is lower than measurement reproducibility). Tests have to be done with higher neutron fluence (100 times higher).

\section{Metal}

Even if the résistance variation of the resonator metal lines has few impact on sensor response, it is necessary to verify that resistive losses remain enough low. Resistor have been fabricated (Fig.5) on glass using 350nm thick Aluminum. The resistance measurement have been done before and after 190 $\mathrm{kGy}$ irradiation. There is no modification of resistivity properties $(<0.4 \%$ shift $)$.

\section{TEST STRUCTURES}

Test structures have been designed (Fig.6) and fabricated (Fig.7, Fig.8) in order to quantify the HDPE outgazing inside a micro-cavity by measuring a $70 \mu \mathrm{m}$ thick silicon membrane deflection.

The membrane deflection measurements have been performed by interferometry method through Glass1 back side, using observation of Newton rings (Fig.9). The error on deflection measurement is given by one ring and is equal to \pm $0.32 \mu \mathrm{m}$.

The samples have been irradiated using $6 \mathrm{MeV}$ focused ebeam providing by electron accelerator (Fig.10). After the first irradiations $(20.7 \mathrm{kGy})$, membrane deflection are measured and the second irradiations are performed $(4.6 \mathrm{kGy})$ following by second membrane deflection measurements. Initial membrane deflection (before irradiation) has been removed to calculate the deflection shift that has been then normalized for $1 \mathrm{mg}$ HDPE (Fig. 11). The sensitivity is around $0.3 \mu \mathrm{m} / \mathrm{mg}_{\mathrm{HDPE}} / \mathrm{kGy}$.
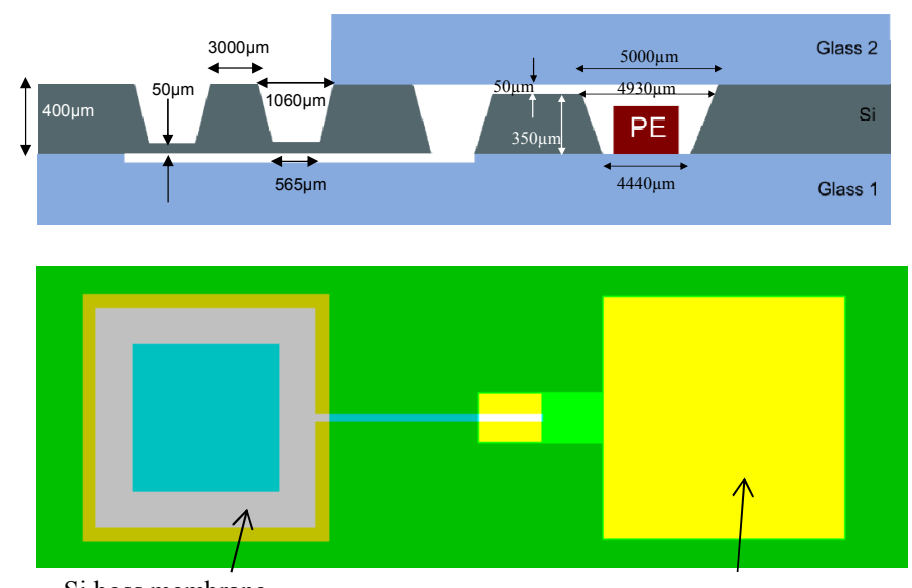

Si boss membrane $(4560 \mu \mathrm{m}$ width $)$

(Top : $5000 \mu \mathrm{m}$ width, Bottom : $4440 \mu \mathrm{m}$ width)

Fig. 6. Cross section and mask view of test structure

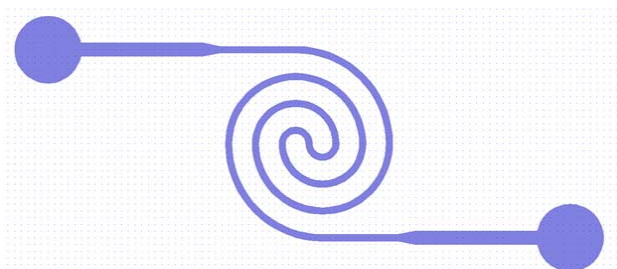

Fig. 5. Design of metal resistor Width: $20 \mu \mathrm{m}$ and Length: $4.62 \mathrm{~mm}$ 
Double side polihed 4 inches Si wafer $(400 \mu \mathrm{m}$ thick)

LPCVD Si3N4 deposition \& patterning + TMAH etching $(50 \mu \mathrm{m})$

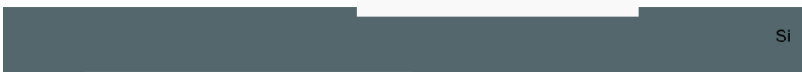

Si3N4 patterning + TMAH etching $(350 \mu \mathrm{m})$

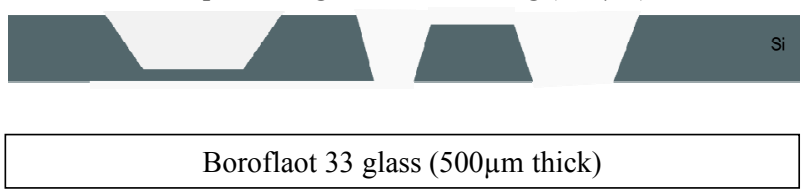

$\mathrm{Cr} / \mathrm{Au}$ deposition and patterning $+\mathrm{HF}$ etching $(\cong 10 \mu \mathrm{m})$

Glass 1

$$
\mathrm{Si} / \text { Glass1 /Glass2 }
$$

Si / Glass 1 anodic bonding $\left(T=450^{\circ} \mathrm{C}, 600 \mathrm{~V}\right.$, vacuum $)+$ Dicing

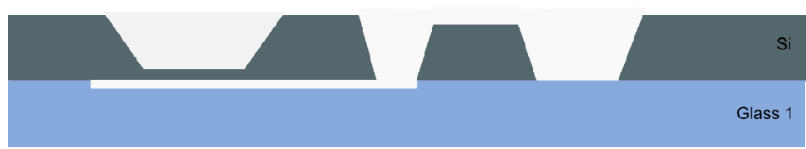

PE filling and annealing $\left(180^{\circ} \mathrm{C}, 15 \mathrm{~min}\right.$, vacuum $)$

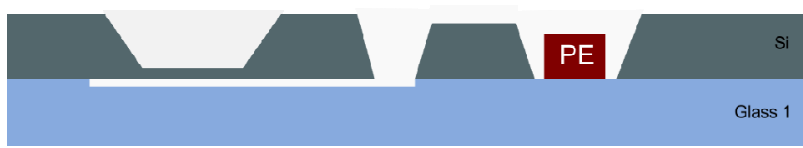

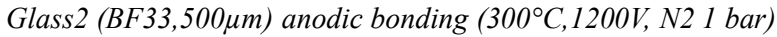

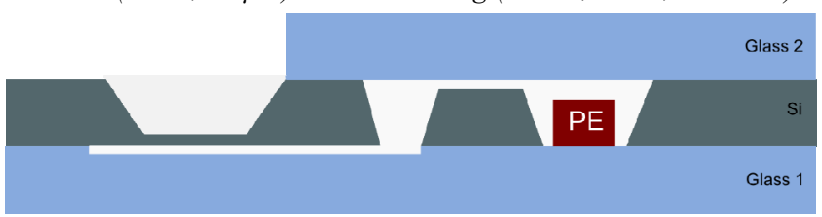

Fig. 7. Process flow

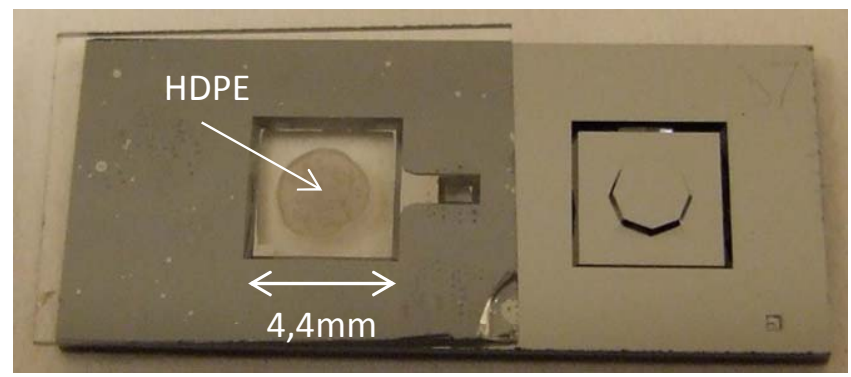

Fig. 8. View of test structure

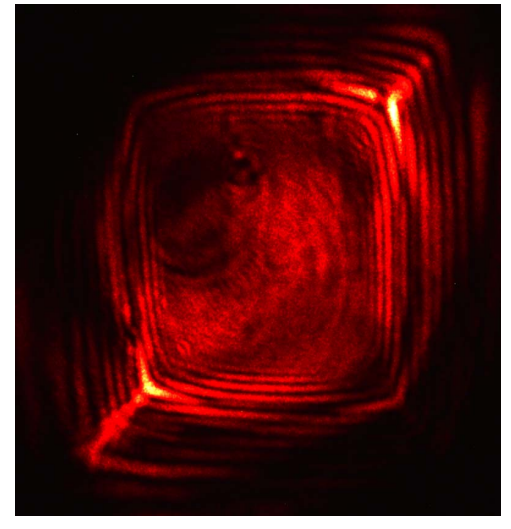

Fig. 9. Example of Newton rings

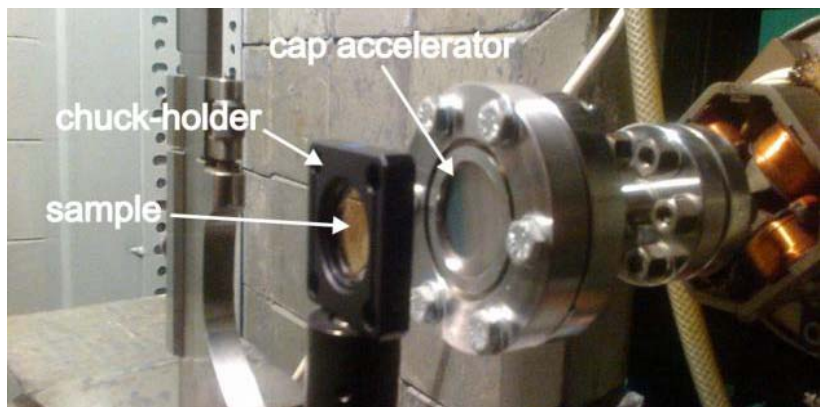

Fig. 10. Set up for electron irradiation with accelerator

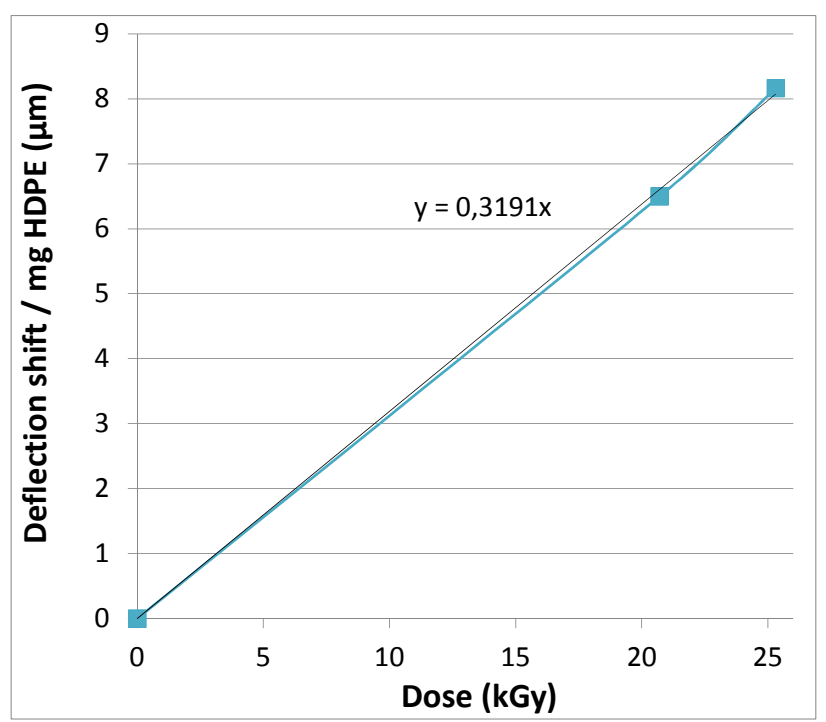

Fig. 11. Deflection shift after irradiation 


\section{TRANSDUCER}

Behavior of pressure transducer has been simulated under air gap (between silicon and resonator) variation (Fig.12). For $400 \mu \mathrm{m}$ thick silicon, resonant frequency shift around $0.8 \% / . \mu \mathrm{m}$ air gap is achieved for initial air gap of $10 \mu \mathrm{m}$ corresponding to $0.25 \% / \mathrm{kGy}$.

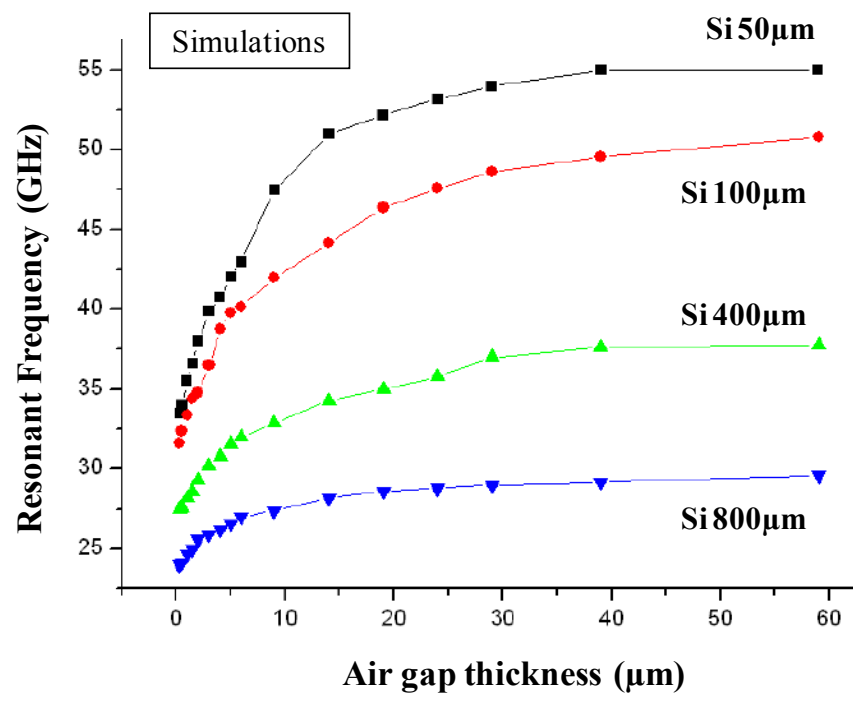

Fig. 12. Resonant frequency shift versus air gap thickness

\section{ACKNOWLEDGMENT}

This work was done in the framework of FP7-MNTERA.NET-DOSIMEMS project funded by EU via Foundation for Polish Science and by Midi-Pyrénées Region.

\section{REFERENCES}

[1] M. Jatlaoui et all "Working Principle Description of the Wireless Passive EM Transduction Pressure Sensor", European Physical Journal Applied Physics, Vol 56, $\mathrm{N}^{\circ} 1$, oct 2011.

[2] I. Augustyniak, et all "MEMS high-doses radiation sensor", International Conference on Solid State Sensors, Actuators and Microsystems (Transducers), June 16-20 2013, Barcelona, Spain 